\title{
Electric vehicles in smart grid and smart city for Petroșani case
}

\author{
Cosmin Rus ${ }^{1, *}$, Monica Leba ${ }^{1}$, Nicoleta Negru$^{2}$, Răzvan Marcuş² and Marius Rîsteiu ${ }^{1}$ \\ ${ }^{1}$ University of Petrosani, Department of Automation, Computers, Electrical Engineering and \\ Energetics, University Street 20, Petroșani, 332006, Romania \\ ${ }^{2}$ Doctoral School of University of Petrosani, University Street 20, Petroșani, 332006, Romania
}

\begin{abstract}
The success of the development of electric vehicles and the increase in demand for their purchase amid greater autonomy of power systems and the development of charging infrastructure also highlights the possibility of using these vehicles as an integral part of a Smart Grid system in the context of sustainable urban development around the extended ideas of the Smart City concept in which other innovative concepts can be integrated. This paper aims to present new research developed around the idea of Smart City in Petroșani, starting from electric vehicles that can serve both as a means of transport and monitoring system of environmental parameters but can also be integrated into the electricity network so that in periods of high consumption it can supply electricity when needed and in periods of over-production to charge their batteries. Although at present at the level of Petroşani there are not many electric vehicles that can become part of the electricity network, this idea is applicable especially in a public or private facility with the possibility of scaling in the future.
\end{abstract}

\section{Introduction}

The term sustainable development is increasingly used in the daily life of each of us. In the municipality of Petrosani, although there are not many investments in terms of sustainable development, there are researches that are advancing rapidly towards achieving this goal. The term "sustainable development" was first used in the Report of the UN Commission on Environment and Development (1987). The concept of sustainable development actually means not endangering future resources through irrational use in the present [1]. Every person in the world can contribute to this goal [2].

Energy systems around the world have been challenged for many years due to population growth and energy consumption. Recent climate change and the growing desire to protect the environment by promoting large amounts of renewable energy sources are a growing concern in the current context [3]. On the other hand, increasing the number of electric vehicles to help achieve a level of sustainable development could put pressure on the electricity generation and distribution network. The question arises in this context whether energy security can be ensured against the background of trying to reduce or eliminate polluting sources of electricity production [4]. Scientific research is being carried out all over

\footnotetext{
*Corresponding author: cosminrus@upet.ro
} 
the world, whose main field of interest is precisely these concerns, and so that at some point an energy independence can be obtained from traditional sources of electricity production.

\subsection{The problem of pollution due to vehicles powered by conventional fuels}

Transport influences and is influenced by the characteristics of economic development but it is often observed that the economic progress of a country comes with pollution problems, especially if the development of any segment of an economy is done without taking into account the component of sustainable development. The transport industry is going through a period of change, so many aspects need to be taken into account, such as increased congestion, noise and chemical pollution or accidents. The current orientation of transport policies is undergoing a shift towards non-directly polluting vehicles, which save space and have a higher degree of safety. The emergence and development of human society imposed the need for transportation. Thus, at the level of this decade, the transport activity came to have a large share in the economy of European countries and beyond. In addition to the positive aspects, there are a number of negative factors that accompany the transport sphere. Road traffic causes more pollution than any other human activity [5]. The main compounds considered as pollutants are the following: carbon monoxide; nitrogen oxides; sulfur dioxide; lead; unburned hydrocarbons.

Once present in nature, these pollutant emissions increase in concentrations due to the fact that naturally their assimilation or destruction occurs after long cycles. In large urban agglomerations, road traffic is responsible for $90 \%$ of the concentrations of carbon monoxide and lead in the air, for $65 \%$ of the concentrations of nitrogen oxides and hydrocarbons and a significant percentage of the suspended particles. It is known that $80 \%$ of cancers are due to harmful substances in the atmosphere. Car emissions are the dominant factor in air pollution, on the main roads, in 24 hours, carcinogenic elements of polycyclic aromatic hydrocarbons nature of over $30 \mu \mathrm{g} / \mathrm{m}^{3}$ can be expelled in the air, and in the slag of the exhaust pipes there are about $200 \mu \mathrm{g}$ of benazepril, one of the main factors that generate cancer [6]. In large cities in Western Europe there are also high concentrations of C.M.A (a saline solution, calcium magnesium acetate) which has the role of keeping roads moist so that dust does not deposit.

\subsection{The concept of smart grid}

The concept of smart grid can be defined as power grids that can intelligently integrate the behavior and actions of all users connected to them - generators, consumers and entities that fulfil both roles - to ensure a sustainable, economical and secure power supply process [7]. Smart grids are also a concept for modernizing electricity grids that integrate electrical and information technologies at any point in the grid, from generation to consumption. The vision of the smart grid aims to improve the reliability, efficiency and security of all elements of electrical systems, from power plants to transmission and distribution and, ultimately, to the end consumer. In particular, electricity networks must allow any renewable energy source to connect without restrictions, even if they have specific operational problems (the quantity and quality of electricity are not always at the same levels) [8].

Especially with regard to equipment for the production of electricity from renewable sources, it is necessary to obtain a high standard of operational safety, both for producers and consumers, to ensure continuity in the supply of electricity to consumers at predefined quality parameters.

In this concept of smart grids there are several secondary concepts that are oriented towards the consumer and his living environment, such as "smart metering", "smart vehicle", "smart home", "smart city" [9]. 
For many years there has been an increasing trend in the number of inhabitants in urban areas, and according to specialized studies it is estimated that by 2050 , in developed countries, the percentage of the population in urban areas will exceed $70 \%$. Large cities tend to expand to include nearby cities, which is also observed in Romania, but on a smaller scale. The world is witnessing a continuous increase in the number of cities that currently have well over 10 million inhabitants. These things are leading to more and more intense research into the integration of smart city and smart grid concepts in any city. The concept of smart city is defined on three main axes, namely people, infrastructure and administration. All current research focuses on defining those elements of a city's electricity grid that define it as a Smart Grid system. The key components of a smart grid are [10]:

- dynamic system based on information technologies;

- $\quad$ high speed, real-time, two-way communications;

- $\quad$ sensors, which allow the rapid diagnosis and correction of certain defects;

- data support for maximum consumption efficiency;

- distributed generation and storage of electricity;

- intelligent / automated power plants;

- control and automation devices in the smart home.

The US National Institute of Standardization and Technology (NIST) addresses the subconcepts of segmented smart grids and defines terms such as vehicle-to-grid (V2G), hometo-grid (H2G), building-to-grid (B2G) or industry-to-grid (I2G) [11]. Thus, the general idea in the smart city network is integration. Technological progress must be oriented in a direction that allows resource and service management.

In many countries, e-mobility is a reality capable of responding concretely and sustainably to travel needs.

The electric vehicle (with two or four wheels), brings many advantages:

- has a less expensive maintenance;

- respects the environment: the electric motor zeroes $\mathrm{CO} 2$ emissions, fine particles and nitrogen oxides while driving;

- zero noise pollution.

Contrary to what one might think, electric cars are not a discovery of these years. In 1987, General Motors won the world's largest rally of solar-powered vehicles, the World Solar Challenge. General Motors decided to build an electric car to launch on the market. GM Impact was born, presented at the Los Angeles Auto Show in 1990 [12].

Electric car sales could grow by up to 86 percent by 2030, on one condition: consumers do not have to buy batteries themselves, according to a study by the University of Berkeley, California. Thus, new business ideas in the field have emerged, such as the one imagined by the Better Place company, which proposes an offer inspired by the mobile phone business. A family that buys an electric car benefits from a number of kilometers included in the contract, the car's battery will be the property of Better Place, which also deals with the installation of charging stations, as well as changing the battery when necessary.

The cost of building battery charging stations (which, in the company's view, will replace the classic gas stations) would be $\$ 320$ billion, partially offset by the fact that the savings made in health, due to reducing pollution, could be $\$ 210$ billion [13].

The prices of electric cars and maintenance costs would be similar to those of gasoline or diesel cars, the cost of power could be even lower than in the case of conventional models, if the price of oil would increase significantly in the coming years.

\subsection{Current trends in electric vehicles}

Last year, 2,846 electric cars were registered in Romania, 89\% more than in 2019. At European level, the trend is even more pronounced. In 2020, at the level of the European 
Union, 538,772 electric cars were registered, an increase of $117.4 \%$ compared to 2019 . These data can be translated as follows: one out of 20 cars registered last year in the EU was electric. Sales of electric cars are expected to increase by more than $30 \%$ annually over the next ten to twenty years, so that soon one in three new generation cars sold in the world will be electric, according to a report [14]. If 2.5 million electric vehicles were sold in 2020, the number of electric vehicles is expected to far exceed 35 million by the end of the $2030 \mathrm{~s}$. In the EU at the end of 2019 there were about 200,000 charging points for electric cars and three quarters of them are in only four countries, while in Romania there were 344 points, according to an ACEA report. In 2020 the number of stations in the country has increased. At EU level, the total is likely to be around 400,000. A report by the European Automobile Manufacturers Association shows that there are 200,000 charging points for electric cars in the EU, but three-quarters of them are in just four countries: the Netherlands, Germany, France and the United Kingdom. Cyprus has only 38, Greece only 61 points, and Bulgaria 135. In Romania there were 344 points, of which 211 normal and 133 for fast charging.

Of the EU's 200,000 charging points, only one in seven is for fast charging. The report notes that the number of places where you can load your car has increased sixfold since 2014, but then the level was extremely low. By 2030, there should be 2.8 million outlets for really good coverage, but the target is not modest at all (14 times more than now) [15].

\section{The purpose of the paper}

The aim of this paper is to conduct an effective study based on current issues in terms of developing new concepts related to the notion of smart city, concerns about the increased level of pollution, especially in large urban centers and increasing number of electric vehicles that are available on the market.

This paper presents a conceptual form that can be developed in Petrosani in terms of creating a smart grid system as well as developing the concept of V2G (vehicle to grid) that will allow an efficient integration of electric vehicles in the energy structure of the city powered by electricity only from renewable sources. A general principle diagram is proposed which presents the realization of a smart grid type system that will have as source of electricity production photovoltaic and wind type systems. All these systems are proposed to be made in Petrosani and due to the fact, that at the University of Petrosani there are undertaken researches regarding small electric vehicles (for two people) and such an electric vehicle is even constructed, namely an electric ATV. In addition to its role in transport, this vehicle can be used as a monitoring platform for pollutant emissions inside the city of Petrosani. The sustainability of this system will also be presented in terms of the demand / supply ratio of electricity for small electric vehicles.

\section{General description of the concept}

The entire research on the construction of an electric vehicle and its integration into the energy system by developing the two-way concept of V2G was carried out in the laboratories of the University of Petroșani. However, it is also proposed to create a smart grid system based on renewable electricity sources [16]. Electric vehicles can supply power, with economic benefits, to the electricity grid during the periods when they are parked and connected to an electrical terminal, either at the user's home or in a public facility. In the context of creating intelligent charging stations, it is necessary to create a communication protocol between each charging station and a control center. This communication protocol can be achieved using LoRa technology. LoRa (low power long range) is a network of low power devices that communicate using a LoRaWAN protocol. The entire operating 
architecture is based on spread spectrum modulation techniques related to CSS (Chirp Spread Spectrum) technology. LoRa and LoRaWAN allow long distance connection for IoT (Internet of Things) devices in different types of industries. In rural areas the distances can be even more than $10 \mathrm{~km}$ with low energy consumption, and thanks to the Forward Error Correction code it improves the resistance against interference [17]. Figure 1 shows the schematic diagram of the entire smart grid system that is to be implemented in Petrosani in order to obtain a certain energy independence using as factors of production only electricity production systems from renewable components (solar energy and wind energy).

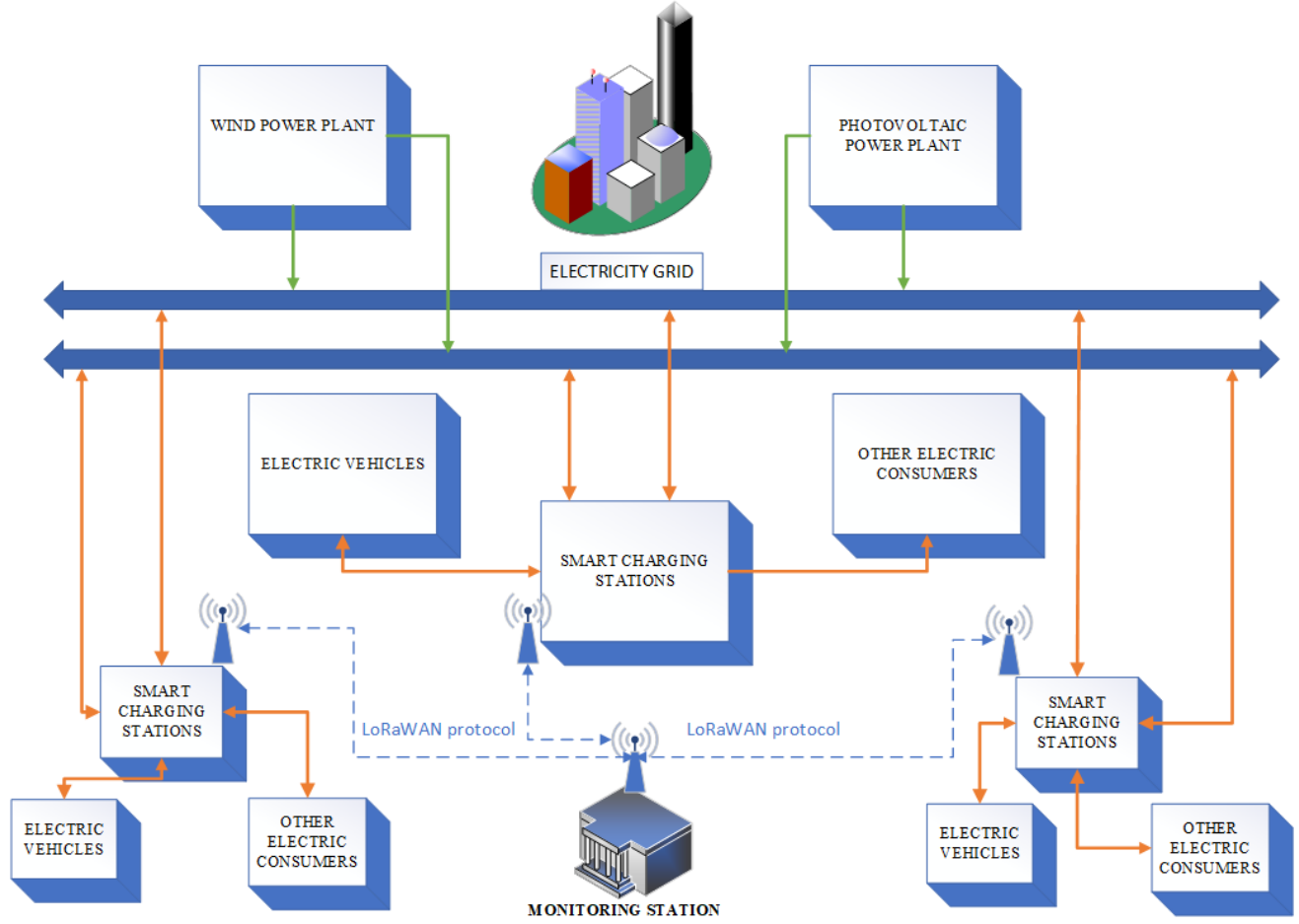

Fig. 1. Concept diagram of a smart grid system and integration of the vehicle-to-grid concept

The electric power available for electric vehicles and consequently their autonomy in terms of the maximum number of kilometers that can be traveled with a single charge is determined by two factors:

a) the limits of the electrical circuit where the electric vehicle is connected,

b) the energy stored in the vehicle battery related to the period in which it is used.

Regarding the network's ability to provide the energy needed for electric vehicles to ensure their proper functioning within a city, the question arises whether a smart grid system based on renewable energy sources is able to provide this goal.

\section{Use of wind and solar resources for electricity production}

In accordance with current studies and taking into account the fact that this paper aims to achieve a smart grid system that will have as suppliers of electricity only systems for producing electricity from renewable sources (wind and photovoltaic) in the area of Petrosani municipality, the question is what is the wind and solar energy potential in this area. 


\subsection{Wind resource for electricity production in Petrosani}

According to the wind map of Romania described in figure 2, which includes the average annual speeds calculated at a height of $50 \mathrm{~m}$ above the ground, the distribution on the Romanian territory of the average wind speed highlights that the main area with wind energy potential is mountain peaks where wind speeds can exceed $8 \mathrm{~m} / \mathrm{s}$.

This area also includes the municipality of Petrosani, where especially in the Parang mountain range, average wind speeds of more than $11 \mathrm{~m} / \mathrm{s}$ are registered. The second area with wind potential that can be used profitably is the Black Sea Coast, the Danube Delta and northern Dobrogea where the average annual wind speed is around $6 \mathrm{~m} / \mathrm{s}$. Compared to other areas, the energy exploitation of the wind potential in this area is also favored by the lower wind turbulence.

The third area with considerable wind potential is the Barlad area (Vaslui county), where there is an average wind speed of about 4-5 m/s. Favorable wind speeds and thus possible good wind potentials are also present in the west of the country, in Banat and especially on the western slopes of the Western Hills.

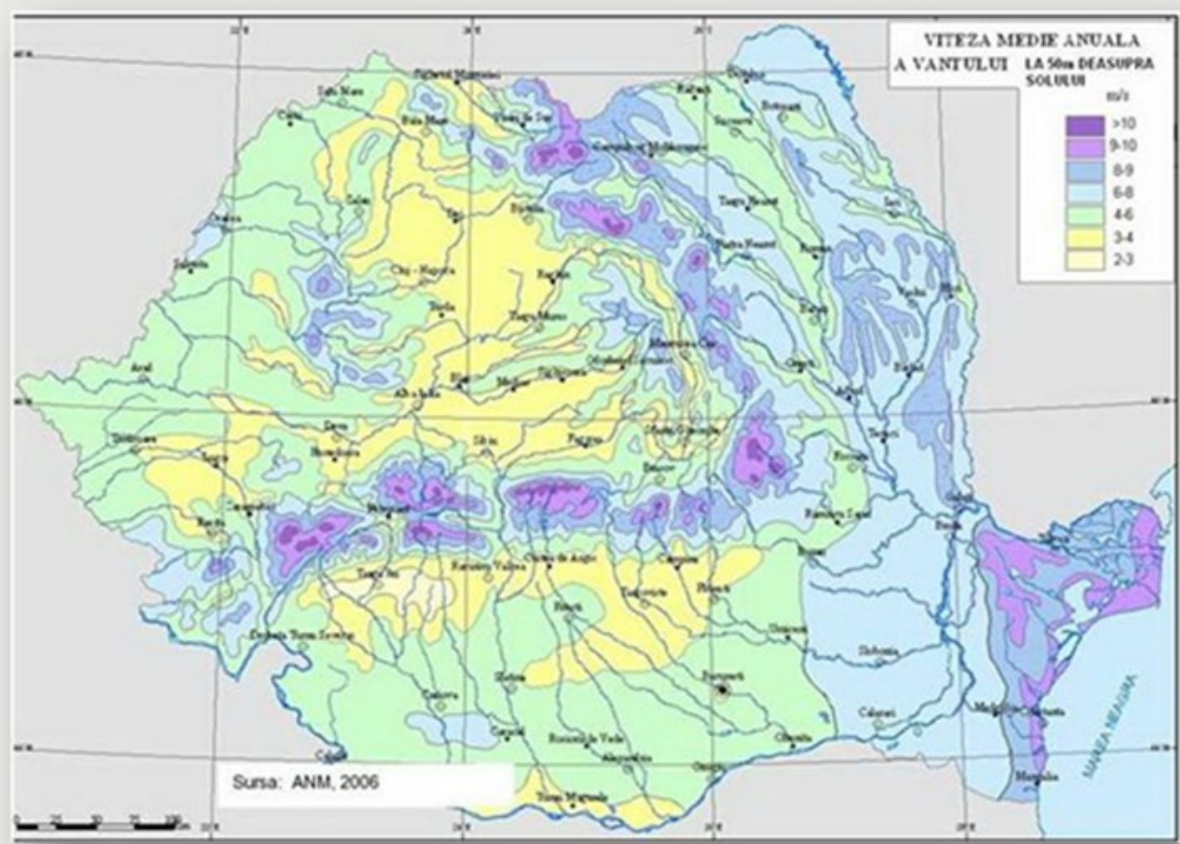

Fig. 2. Average annual wind speed in Romania (source: ANM Romania)

As many specialized works $[18,19]$ show, the kinetic energy of the wind can be transformed into electricity using the formula:

$$
E_{C}=\frac{m * v}{2}
$$

where $m$ represents the mass in kilograms and $v$ represents the wind speed in meters/second. According to Albert Betz's theory, through wind systems we can use about $59 \%$ of the total available wind energy.

If we take into account any kind of wind turbine currently encountered, its final power is given by the formula:

$$
P=\frac{\rho * \pi * R^{2} * v^{3}}{2}
$$


where $\rho$ is the air density at an average temperature of $15^{\circ} \mathrm{C}$, the air density is measured in $\mathrm{kg} / \mathrm{m}^{3} ; v$ is the wind speed measured in $\mathrm{m} / \mathrm{s}$ and $R$ represents the radius of the turbine blades measured in meters.

The energy from a wind source that can be obtained in an interval of one year can be calculated as an integral of the power depending on the wind speed in the mentioned interval:

$$
E=\int_{0}^{\infty} P(v) u(v) d v
$$

where $P(v)$ is the wind power (with values that can go from $3.5 \mathrm{~m} / \mathrm{s}$ to $25 \mathrm{~m} / \mathrm{s}$ ) and $u(v)$ is a function of the probable density of the wind speed.

In order to calculate the wind energy potential in a certain area, the density of the wind energy flow must be first determined using the formula:

$$
P=\frac{\rho * v^{3}}{2}
$$

where $\rho$ represents the density of the air and $v$ represents the speed of the wind.

The average density of the energy flow for a certain location and over a relatively long-time interval as an extension ( $\mathrm{T}$, of the order of years) defines the wind potential of a certain location by means of the formula:

$$
\varepsilon=\lim _{T \rightarrow \infty} \frac{1}{T} \int_{0}^{T} P(t) d t
$$

The same can be written in the form of a formula that defines the average annual energy that passes over a certain unit of area:

where $\mathrm{T}=1$ year or 8760 hours.

$$
E=\int_{0}^{T} P(t) d t
$$

From all the equations written above it is observed that for a certain location in order to make the most accurate calculations we need to know the wind speed and duration in a certain time interval.

In this case, data provided by the ANM (National Meteorology Administration) and an instrument developed within the European Commission that monitors the renewable energy potential globally were used.

Such as from relations (4) and (6) it can be deduced that:

$$
E=\frac{\rho}{2} \int_{0}^{T} v^{3} d t
$$

In this new relationship (7), the weighted average air velocity is introduced as a simple function of time. It is known from specialized studies that wind speed values have a discrete random character so a calculation as accurate as possible must make a statistical processing of all data but in this paper we will calculate the wind potential of the Petrosani area using a finite number of terms. We used annual average data taken from other works or data provided by ANM.

Due to its geographical position and altitude, the climate of Petroşani should be submountainous, but if we take the temperature of the warmest month (July with an average of $\left.16.7^{\circ} \mathrm{C}\right)$ and the average annual temperature $\left(6^{\circ} \mathrm{C}\right)$ the climate is closer to the low altitude mountain one.

Hot days with average temperatures above $30^{\circ} \mathrm{C}$ are fewer in Petroșani than in other regions considered colder, and the number of summer days with temperatures above $25^{\circ} \mathrm{C}$ is 50 days. The average annual rainfall is $700-800 \mathrm{~mm} /$ year. Days with high fog reach over 200 per year. The average annual wind speed is between 10 and $11.5 \mathrm{~m} / \mathrm{s}$ depending on the altitude area.

It will further be considered that the average annual wind speed is $10,75 \mathrm{~m} / \mathrm{s}$. The wind turbine is located at a height of 50 meters above the ground, the average annual humidity is $0.007 \mathrm{~kg} / \mathrm{m}^{3}$ and the air density corresponding to the average annual temperature of $6^{\circ} \mathrm{C}$ is $1,269 \mathrm{~kg} / \mathrm{m}^{3}$. The wind power for wind speed of $5 \mathrm{~m} / \mathrm{s}$ for the temperature of $6^{\circ} \mathrm{C}$ is 79.31 $\mathrm{W} / \mathrm{m}^{2}$. So if we perform the calculations according to (4): 


$$
P=\frac{\rho * v^{3}}{2}=\frac{1,269 * 10,75^{3}}{2}=788,23 \mathrm{~W}
$$

To calculate the energy potential for a day ( 24 hours) the formula can be used:

$$
E=\int_{0}^{T} P(t) d t=18917,69 \mathrm{~W} / \text { day }=18,918 \mathrm{~kW} / \text { day, }
$$

To verify and validate the result obtained in (9) is considered that $\mathrm{T}=86400 \mathrm{~s}$ and is calculated to obtain the wind potential in $\mathrm{J} / \mathrm{m}^{2}$

$$
E=\frac{\rho}{2} \int_{0}^{T} v^{3} d t=\frac{86400 * 1,269 * 1242,29}{2}=68103708,525 \mathrm{~J} / \mathrm{m}^{2},
$$

If $(10)$ is divided by $3.6^{*} 10^{6}$, the energy expressed in $\mathrm{kWh} / \mathrm{m}^{2}$ is obtained:

$$
E=18,918 \mathrm{kWh} / \mathrm{m}^{2}
$$

Thus, for 10 such wind turbines that have a blade radius of 3 meters and have been installed in a suitable environment in the Jiu Valley, about 560kWh of electricity can be obtained [20].

\subsection{Solar resource for electricity production in Petrosani}

Romania is in the European B zone of sunshine, which offers the inhabitants real advantages to save thermal energy, respectively money, if they use solar energy. Depending on the geographical area, Romania is divided into three main sunny areas as shown in figure 3.

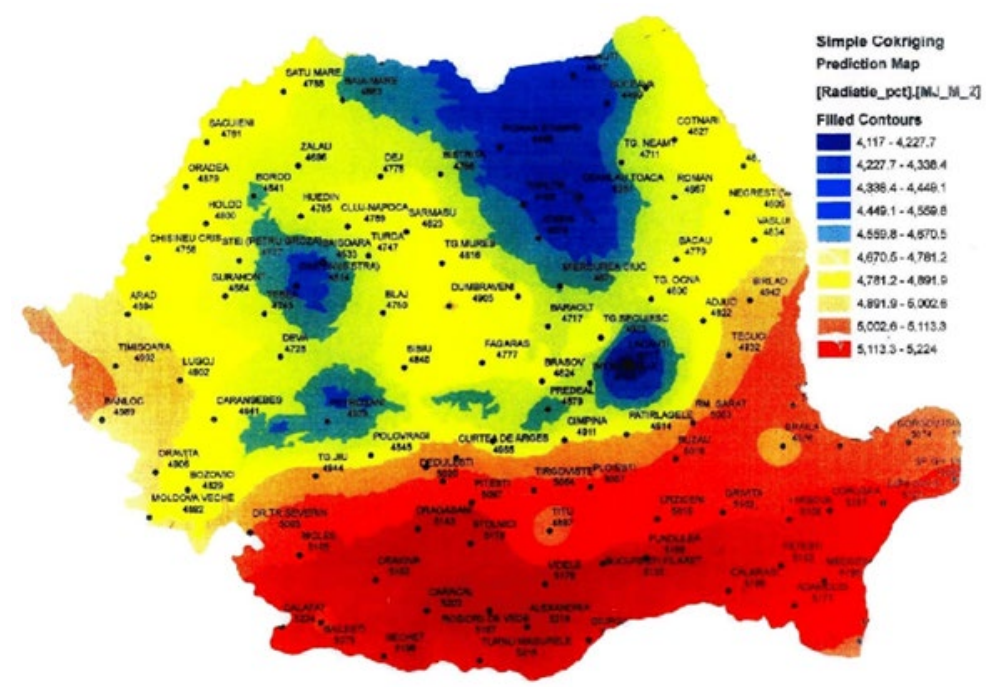

Fig. 3. Distribution of solar potential in Romania (source: ANM Romania)

The red zone $\left(>1650 \mathrm{kWh} / \mathrm{m}^{2} /\right.$ year) coincides with the southern zone, respectively Oltenia, Muntenia, Dobrogea and the south of Moldova. The yellow zone $\left(1300-1450 \mathrm{kWh} / \mathrm{m}^{2} /\right.$ year) here we find the Carpathian and sub-Carpathian regions of Muntenia, Transylvania, the middle and the northern part of Moldova and the whole Banat and the blue zone $(1150-1300$ $\mathrm{kWh} / \mathrm{m}^{2} /$ year) mountain regions.

Romania is located in a geographical area with good solar coverage, with 210 sunny days per year and an annual flow of solar energy between $1000 \mathrm{kWh} / \mathrm{m}^{2} /$ year and $1700 \mathrm{kWh} / \mathrm{m}^{2}$ / year. From this amount of energy can be captured between 600 and $800 \mathrm{KWh} / \mathrm{m}^{2} /$ year.

The potential for the use of solar energy in Romania is relatively important. There are areas where the annual solar energy flow reaches up to $1450-1600 \mathrm{kWh} / \mathrm{m}^{2} /$ year, in the area of the Black Sea Coast and Dobrogea as in most southern areas. Although the solar potential in Romania is high, in Petrosani it is observed that the solar energy potential is quite low but it is not insignificant and can be used with great success. However, in Petrosani there are 
several public or private facilities that successfully manage to produce renewable energy with the help of solar radiation.

Regarding the potential for electricity production using photovoltaic panels in Petrosani according to Photovoltaic Geographical Information System (a software product of the European Commission) value of $1398,96 \mathrm{kWh}$ for the in-plane irradiation indicator is found. If specific calculation formulas are applied starting from the value of the yearly in-plane irradiation indicator of $1398.96 \mathrm{kWh}$, it results that an average solar energy potential of $3.83 \mathrm{kWh} / \mathrm{m}^{2}$ can be obtained during a day using a standard photovoltaic panel.

If it is considered at the level of Petrosani the incorporation of several photovoltaic systems on the roofs of several buildings so as to obtain a surface covered with solar panels of about $10,000 \mathrm{~m}^{2}$, it is concluded that about $383 \mathrm{MWh}$ of electricity can be supplied daily.

After applying the calculations presented above, it can be stated that at the level of Petrosani municipality a smart grid system can be created based only on electricity production systems using renewable solar and wind resources. It is true that the production of electricity from wind and solar sources is much lower in this area due to the climate and geographical location, but it should be noted that especially the systems for producing electricity from solar resources are advantageous.

In the context of creating a smart grid system in Petrosani, it is proposed to take into account the increase in the number of small electric vehicles and the average useful power, especially when traveling in the city.

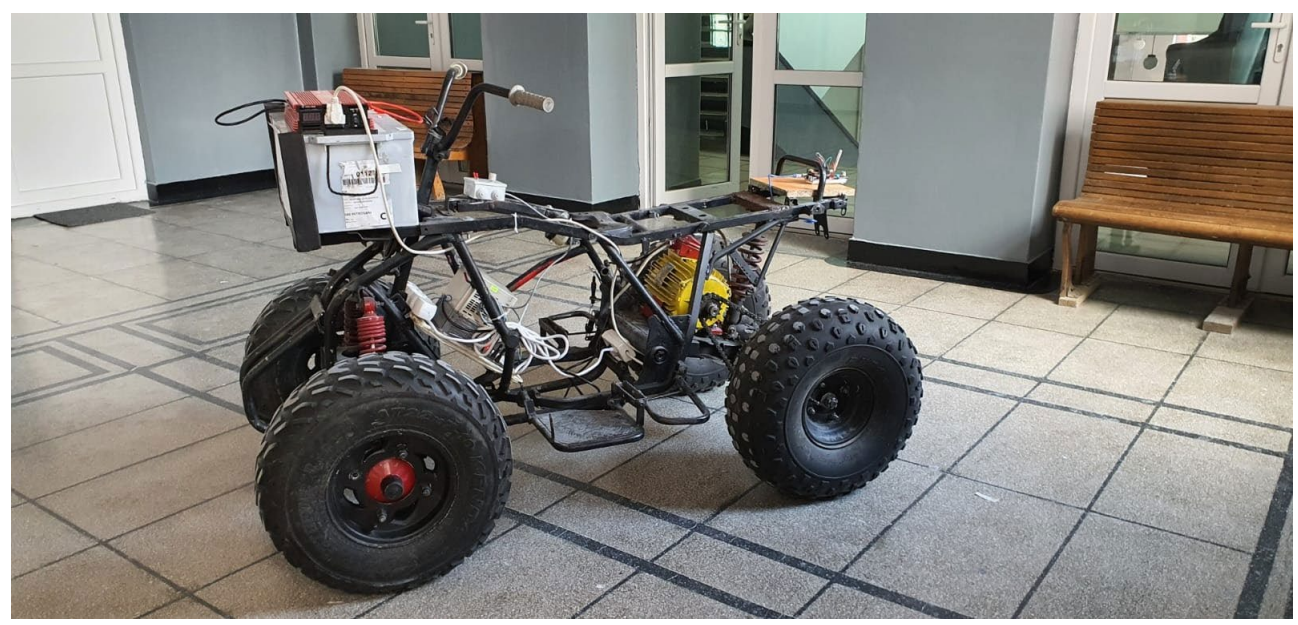

Fig. 4. Electric ATV

Thus, if we consider as a small electric vehicle for two people an electric ATV made in the laboratories of the University of Petrosani (figure 4), we can make an energy calculation on the sustainability of the entire smart grid system proposed in this paper. The built-in electric ATV has a $2.2 \mathrm{~kW}$ three-phase asynchronous motor. The control of the three-phase motor is done by means of a frequency converter that is powered by a power inverter that takes the electricity from a $12 \mathrm{~V}$ and $120 \mathrm{Ah}$ car battery [21]. In the best case, if we consider at the level of Petrosani a population of 40413 inhabitants of which about $70 \%$ can drive such an electric vehicle, it results that we would have 28289 inhabitants who can use this means of transport. Like a conventional car with a heat engine and electric vehicles, it must be powered and the problem of the impact it can have on the entire local smart grid energy system is raised. If we take as a reference model a small electric vehicle specially designed for two people with a slightly larger battery ( $12 \mathrm{~V}$ and $200 \mathrm{Ah})$ than the electric ATV presented above and a population of 28,289 inhabitants who can purchase and use such a vehicle results in a 
total consumption of the smart grid system of $67.9 \mathrm{MWh}$ equivalent to $17.72 \%$ of the total energy production only from the solar component. In order to have a smart grid system in which the vehicle-to-grid concept is perfectly integrated, our own intelligent charging station was created based on a SmartEVSE controller. This station can provide a charging current of up to 44Ah. The entire intelligent charging station has a very simple, modular construction and has a relatively low production cost. It consists of the SmartEVSE controller, a NO contactor, 3 current sensors and a type 2 socket as shown in figure 5 .

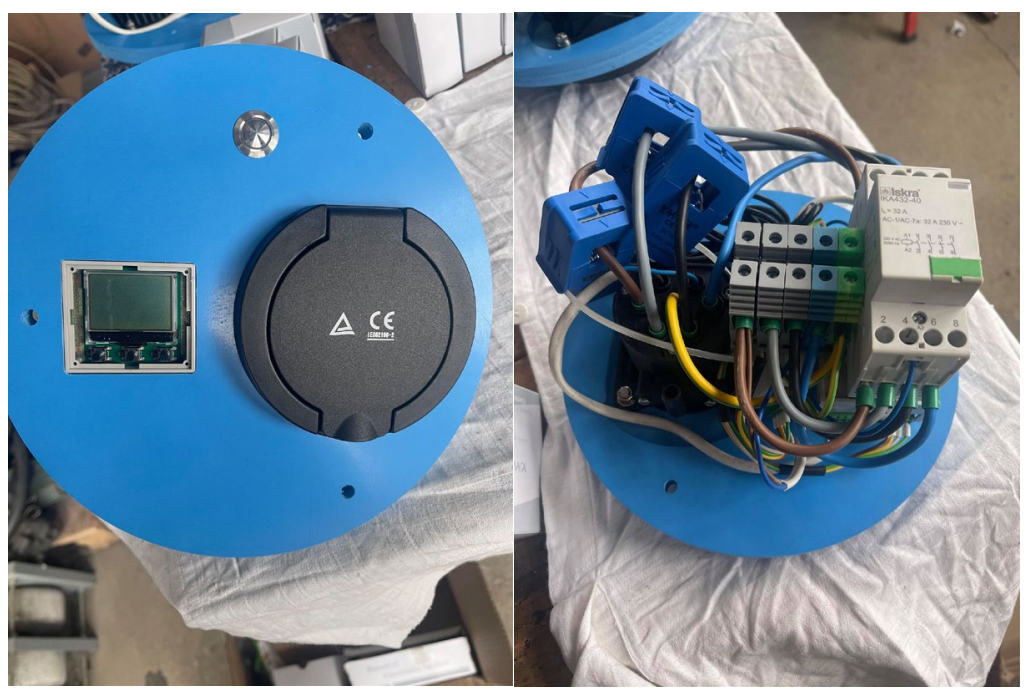

Fig. 5. Charging station built with SmartEVSE controller

Starting from the production of electricity using renewable sources, using electric vehicles integrated in the entire system and also benefiting from the advantages of using an intelligent electric charging station, we can say that we can obtain an efficient smart grid system in Petrosani $[22,23]$. The intelligent charging station for electric vehicles, in addition to being able to charge the batteries in a relatively short time, can also manage any energy requests from the network when the vehicle is parked, thus becoming an energy supplier [24].

\section{Conclusion}

This paper was carried out starting from the construction of an electric vehicle (electric ATV) within the University of Petrosani. This vehicle was made mostly of recycled components and parts and the problem was to make a power supply system from renewable sources so that the vehicle is truly environmentally friendly. Thus, it was proposed to build a smart grid system in the city of Petrosani (consisting of renewable energy sources and equipment and electric vehicles) that would integrate extensively the concept of V2G (vehicle-to-grid). The energy potential from wind and solar sources was calculated for the entire city with the possibility of scaling in the future. Although the energy potential is relatively good due to the high costs in terms of making installations with wind turbines, a system of photovoltaic panels spread on the roofs of buildings in the city is preferred. The need for electricity only to power all the electric vehicles needed for a percentage of $70 \%$ of the population of Petrosani is $17.72 \%$ of the production potential only from photovoltaic sources. So, it can be said that the whole concept is sustainable and can be used. Regarding the concept of vehicleto-grid, the own intelligent charging station for electric vehicles has been created and thus 
another point of the development of the smart grid system can be reached by the fact that electric vehicles can become prosumer units if necessary, within the general network of production and supply of electricity based only on renewable sources. Prosumers are those who not only consume energy from the electricity grid, but also produce and deliver energy from renewable sources. They produce for their own consumption and inject the surplus into the network, for a fee, based on a sale-purchase contract with their electricity supplier. Although it seems hard to believe at the level of each city, such a system can be developed and so it can be obtained if not a total energy independence at least a partial independence from conventional forms of electricity production.

\section{References}

1. L.I. Cioca, L. Ivascu, A. Turi, A. Artene, G.A. Găman, Sustainability, 11(22) (2019)

2. D.N. Fîță, C. Barb, D. Păsculescu, L. Pană, MATEC Web Conf., 290, 12010 (2019)

3. A. M. Omer, J Renew. Sust. Energ. Rev., 1(5), 053101 (2009)

4. S. Riurean, S. Rosca, C. Rus, M. Leba, A. Ionica, Advances in Intelligent Systems and Computing, 724, (Springer, Cham., 2018)

5. Pătrășcoiu, C. Rus and N. Negru, Proceedings of the 21th International Carpathian Control Conference (ICCC) (2020)

6. N. Pătrășcoiu, C. Rus, C. Roșulescu, N. Negru, Electrical Engineering, 22 (2020)

7. V. Tsiatsis, S. Karnouskos, J. Höller, D. Boyle, C. Mulligan, Internet of Things (Second Edition) (Academic Press, 2019)

8. J. F. Martins, A. G. Pronto, V. Delgado-Gomes, M. Sanduleac, Pathways to a Smarter Power System (Academic Press, 2019)

9. A.H Mohd Aman, N. Shaari, R. Ibrahim, Int J Energy Res., 1 (31) (2021)

10. G. Dileep, Renewable Energy, 146, 2589-2625 (2020)

11. R. DeBlasio, C. Tom, Proceedings of the 2008 IEEE Energy 2030 Conference, Atlanta, 1-7 (2008)

12. M. Shnayerson, The Car That Could (Random House, New York, 1996)

13. The electric vehicle world sales database, Available on https://www.evvolumes.com/

14. Deloitte Insight's report "Electric vehicles: Setting a course for 2030", Available on https://www2.deloitte.com/uk/en/insights/focus/future-of-mobility/electricvehicle-trends-2030.html

15. EC, 2020, '2050 long-term strategy', European Commission

16. C. Rus, N. Negru, N. Patrascoiu, J. Environ. Prot. Ecol., 20(3), 1451-1461, (2019)

17. C. Rus, R. Marcus, L. Pellegrini, M. Leba, M. Rebrisoreanu, A. Constandoiu, IOP Conf. Ser.: Mater. Sci. Eng., 572, 012091, (2019)

18. I.O. Muntean, Mechanical Engineering, 9 (2007)

19. M. Deliu, G.H. Deliu, Recent, 8(2), 91-96, (2007)

20. M. Leba, A. Ionica, R. Dobra, V. Pasculescu, Environmental Engineering and Management Journal, 13(6), 1365-1370. (2014)

21. C. Rus, M. Leba, R. Marcuş, L. Pellegrini, A. Costandoiu, MATEC Web Conf. 305 00043 (2020)

22. N. Patrascoiu, C. Rus, Electrical Engineering, 18 (2016)

23. L. I. Cioca, I. Ivascu, A. Turi, A. Artene, G.A. Găman, Sustainability, 11(22) (2019)

24. S. D. Volosciuc, M. E. Dragosin, MATEC Web Conf., 29001021 (2019) 